\title{
Integrated co-operative governance in the context of sustainable development
}

\author{
EJNEALER ${ }^{1} A N D M N A U D E^{2}$
}

\begin{abstract}
The rapid global development is mostly economically driven and made up of complex country-specific problems. Although sustainable development (SD) is a well established concept and an urgent global challenge, differing levels of progress had been made in organisations, communities and countries. To facilitate consistency of understanding, the authors accept the definition of 'sustainable development' as including the economic, social and environmental dimensions. Furthermore, they argue that these dimensions are not functioning as separate silos but are interdependent and grounded in legislated governance frameworks from where co-operative governance $(\mathrm{COG})$ realizes as an option to facilitate an integrated approach. The article discusses the challenges in the facilitation of COG and suggests practical guidelines for implementation to facilitate improved integration.

Keywords: Sustainable development, governance, co-operative governance, integrated, organising, and communication.

Disciplines: Public Administration, Public Management, Social Welfare, Environmental Management, Municipal public service delivery, Social Development, Organisational Behaviour, Co-operative Governance, Communication, Sustainable Development, Sustainable Organisational Development.
\end{abstract}

\section{Introduction}

The current rapid world-wide development is mostly driven by economic development and made up of a range of complex problems unique to each country. One such a problem is overpopulation which leads to disastrous effects on a planet already exploited. As a result, earthly resources will become extinct if there is no firm and definite ongoing commitment to sustainability. Along the same line of

1. School for Social \& Government Studies, North-West University, Private Bag X6001, Potchefstroom, South Africa, 2520, Tel: (018) 299 4332, E-mail: eric.nealer@nwu.ac.za

2. Curtin Graduate School of Business (CGSB), Curtin University, GPO Box U1987, Perth, Western Australia, 6845, Tel: +61 89266 7615, Email: Marita.Naude@gsb.curtin.edu.au 
thinking, there had been a number of environmental catastrophes in latter years of the $20^{\text {th }}$ century. Consequently, there is an urgent need to move towards an integrated, implementable and realistic approach to sustainable development (Patra, 2008; Cho \& Roberts, 2010). World-wide there has been a notable shift in the public concern regarding environmental issues and the related corporate performance (Cho \& Roberts, 2010). Furthermore, society's expectations of business are changing and companies are now expected to act responsibly towards both society and their shareholders (Baden, Harwood \& Woodward, 2009).

At a first glance, enhancing effective sustainable development seems to be a manageable task as sustainable development is not a new concept (Baumgartner \& Korhonen, 2010) and it is one of the most widely used words today (Patra, 2008). Although sustainable development is an urgent, global and long-term challenge, different levels of practical and realistic progress have been made and effective long-term outcomes have been attained regarding sustainable development in the day-to-day functioning of various organisations and communities. Varying levels of effective progress have been made regarding development and effective implementation of national, regional and international policies (Baumgartner \& Korhonen, 2010). It is a well-known fact that the manifestation of economic growth, social welfare improvement and more effective and sustainable management of the environment in especially developing countries is of an uneven nature (Lieferink, 2010).

Based on the shift in thinking and assigned responsibility, both managers and public policy-makers are trying to manage sustainability more effectively but face a complex range of difficult challenges. These challenges include the more than 90 definitions of sustainable development (Becker, 2010), concepts which are very broad and there seems to be a lack of applicable, tested and validated comprehensive frameworks and/or models, with applicable and effective guidelines for implementation (Jabbour \& Santos 2008). Moreover, sustainable development and the success of sustainability is a value judgment; some areas could only be assessed by inference from what is observable and not always through quantifiable measurement (Becker, 2010; Wallis, Kelly \& Graymore, 2010). Globally, both managers and public policy-makers are researching approaches and/or frameworks to assist them (Wallis, Kelly \& Graymore, 2010; Morrow \& Rondinelli, 2002).

In attempting to address these approaches and/or frameworks more effectively, the place and role of co-operative governance (COG) has been identified as a 'new vehicle' towards more effective sustainable development $(\mathrm{SD})$. The authors of this article are of the opinion that effective COG could facilitate and enhance improved SD and acknowledge that COG is regarded as a new approach to governance (Department of Environmental Affairs, Online, 2003). In this new approach, there is a shift away from the narrow focus of governance to a broader focus. This includes the process by which governments are selected, monitored and replaced; the capacity of the government to effectively formulate and implement sound public policies; and the respect of citizens and the state for the institutions that govern economic and social interactions among them. In a broader focus, a wider range of governance mechanisms are used which are concerned with the growing positions and roles of associations and partnerships that reflect the dynamic and interactive nature of co-ordination and integration (Department of Environmental Affairs, 2006:16-18).

The concept of 'co-operative governance' (COG) has also been termed as 'multilevel governance' (Benz \& Eberlein in Bulkeley et al, 2003) and 'co-operative development planning' (Nelana, 2005). For the purpose of this article, COG implies both the narrower concept of governance and mechanisms shared between different government departments and a broader concept of governance, which includes external groups and influential individuals such as the public / stakeholders and the industrial sector (Forsyth in Boer et al., 2003). Along this line of reasoning, the following four questions arose:

- What key dimensions should be contained within a sustainable development context? 
- What key dimensions should be contained within a COG context to facilitate sustainable development?

- What are the challenges managers might face in an attempt to implement both sustainable development strategies and activities through effective COG?

- What practical guidelines could managers use to guide them to implement both sustainable development strategies and activities through effective COG?

In an effort to address these four questions, the overall aim of this article is two-fold. Firstly, to analyse sustainable development and COG dimensions and to identify potential challenges for managers in implementing effective sustainable development strategies and activities within a COG context. Secondly, to provide practical guidelines for the implementation of effective COG to facilitate sustainable development.

Consequently, this article adds value from both a theoretical and practical perspective. From a theoretical perspective, it provides an analysis of sustainable and COG dimensions. Furthermore, it analyses the challenges related to effective COG strategies to enhance sustainable development. From a practical perspective, it can potentially raise renewed awareness among managers and public policymakers regarding the importance of implementing COG to facilitate sustainable development.

The remainder of this article is structured in three sections. Firstly, various literature sources which the authors used as a basis for their arguments, are identified. Secondly, the challenges managers might face trying to implement sustainable development strategies and activities are discussed. Lastly, practical guidelines for the implementation of more effective COG to facilitate sustainable development, are proposed.

\section{Literature review}

\section{Sustainable development (SD)}

$\mathrm{SD}$ originated in relation to explicitly green issues, but has evolved to reflect a process that meets the needs of the present without compromising the ability of future generations to meet their own needs. Often called intergenerational equality, the idea is that natural resources should be shared, not just with people who are alive on the planet today but also with future generations of Earth's inhabitants. Whilst a certain amount of the planet's resources can be used, the earthlings should never entirely deplete a natural resource (Brundtlandt in Hoverstadt \& Bowling, 2005).

Economic development, especially in India and China, could have a drastic and devastating effect on the already exploited resources on the planet. Furthermore, India and China contain two thirds of the total world population which adds increasing pressure. There is an urgent need to turn around from the destructive path of inevitable self-destruction towards an integrated, practical, realistic approach to sustainable development (Patra, 2008).

Sustainable development strategies (including economic, social and environmental dimensions) date back to the United Nations Conference on Environment and Development (UNCED) of 1992 with the aim to address urgent problems of environmental protection and socio-economic development. Agenda 21 ('Rio Declaration'), Chapter 8 (8.7), which was produced at the 1992 Conference, proposed that a National Strategy for Sustainable Development (SD) should harmonize as well as build upon various economic, social, and environmental policies and plans operating in countries. The Commission on Sustainable Development was created to monitor and report on the implementation of agreements (UN, 1992; UN 1997). Furthermore, it was clear that SD strategies needed to focus on three areas, namely: economic, social and environmental. These SD areas are consistent with the 1987 
Brundtland Commission Report's classic description of SD suggesting that equity, growth and environmental maintenance are simultaneously possible (Brundtland, 1987). Five years later at the Rio +5 Summit it was agreed that the formulation of SD strategies ought to be completed in all countries by the year 2002 (UN, 1997). In 2002, at the World Summit on Sustainable Development (WSSD) in Johannesburg, South Africa, the aim was to measure progress on Agenda 21 principles and to encourage new commitments and actions to achieve sustainable development (WSSD, 2002). The latter years of the $20^{\text {th }}$ century saw a number of environmental catastrophes (for example, Chernobyl nuclear power plant accident in 1986, Three Mile island nuclear power plant accident in 1979 and Exxon Valdez Oil Spill in 1989) triggering a notable shift in the public concern regarding environmental issues and corporate performance (Cho \& Roberts, 2010).

Society's expectations of business are changing and companies are now expected to be responsible and accountable to both their shareholders and society. This lead to an increasing emphasis on and commitment to sustainable development (Baden, Harwood \& Woodward, 2009). Within this context, there is an increased call for companies to act and conduct their business in a sustainable manner. Previously, organizations doubted their ability to successfully compete if costs were increased as a result of sustainability strategies. That opinion has changed and currently organisations are proud to announce environmental protection, strategies and activities (Szwajkowski, 2000).

Across the world, managers and public policy-makers are trying to determine success and effectiveness of both sustainability strategies and outcomes. To complicate this task, more than 90 definitions for sustainable development exist (Becker, 2010) although it is one of the most widely used words today (Patra, 2008). Furthermore, sustainability is a value judgment and means different things to different people, organisations and institutions, and some aspects can only be assessed by inference from what is observable. Therefore, there are many attempts to measure progress towards sustainability (Becker, 2010; Wallis, Kelly \& Graymore, 2010). Over time, numerous tools were developed at global (e.g. United Nations Commission on Sustainable Development), regional (e.g. Eco-Management and Audit Scheme, EMAS, in Europe) and local (Sustainable Seattle) levels. However, tools deliver varying outcomes and levels of assessment which could be frustrating and even misleading, prompting managers and public policy-makers to seek guidance and formulate frameworks towards developing strategies to facilitate sustainability (Wallis, Kelly\& Graymore, 2010; Morrow \& Rondinelli, 2002).

Frameworks assist to organise the disparate aspects of sustainability to create particular indicators to measure the achievement of these indicators. However, the mere existence of a framework does not necessarily guarantee the desired outcomes but assists managers and public policy-makers to develop more effective structured systems and, furthermore, guides regulatory compliance performance and provides a system for continuous quality monitoring and improvement (Becker, 2010; Wallis, Kelly \& Graymore, 2010).

For the purpose of this article the authors accept the SD definition that clearly includes the economic, social and environmental dimensions (UN, 1992; UN 1997) and which is consistent with the 1987 Brundtland Commission Report's classic description of SD suggesting that equity, growth and environmental maintenance are simultaneously possible (Brundtland, 1987). The authors also acknowledge and propose that the connections between the sustainable development dimensions (economic, social and environmental) are inescapable as they are inextricably interrelated and interconnected. This entails the incorporation of the collective and integrated synergies between the embedded environmental, economic viability (including technology), and social equity (including culture and politics) systems which are underpinned by or grounded in the facilitating system of governance and $\mathrm{COG}$ in a holistic quest towards effective public decision-making and policy implementation (Glasson \& Wood, 2009). Figure 1 below depicts an exposition of a three-legged stool, with each leg representing one of the three dimensions of sustainable development, and the links between SD and COG: 


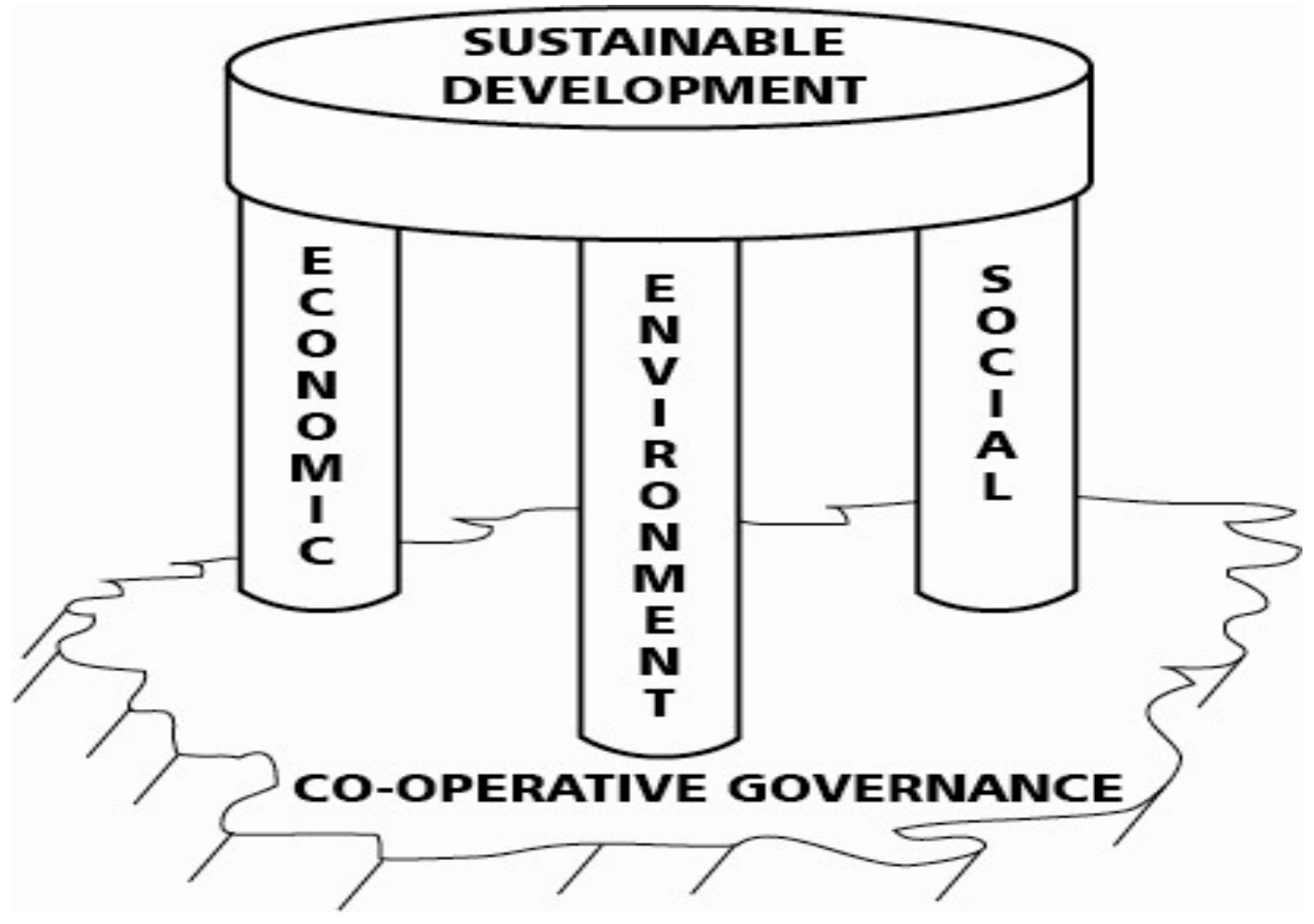

Figure 1: Depiction of links between SD and COG. (Source: Author's [Nealer] own work)

The various environmental, social and economical dimensions do not function in separate silos but are dependent on each other via another dimension, namely: the grounding and legislated governance framework. These four dimensions which are dynamic and constant within a SD context, include the following:

- Environmental dimensions such as the surroundings within which humans exist and are made up of:

0 the land, water and atmosphere of the earth;

- micro-organisms, plant and animal life;

$\circ$ any part or combination of the aforementioned two aspects and the interrelationships among and between them; and

○ the physical, chemical, aesthetic and cultural properties and conditions of the foregoing that influence human health and well-being (RSA, 1998:Section1.1[xi]).

- Social dimensions such as meeting the diverse needs of all people in existing and future communities, promoting personal well-being, social cohesion and equal opportunity for all (Torbay Council, Online). Islam et al. (2003) are of the opinion that the social dimension emphasises the enrichment of human relationships and achievement of individual and group aspirations.

- Economical dimensions such as economic growth, exports, foreign exchange reserves, foreign direct investment, official exchange rate, and public sector deficits come to the fore (James, 2003). In this sphere, challenges to countries' economies include the constraints on rising fiscal expenditures caused by capacity limitations, attempts to keep inflation down when oil and energy costs are rising, and the selection, funding and management of second economy interventions that expand employment, create assets, build the skills base and contribute to solving social problems. 
- Governance as the facilitative grounding dimension of the aforementioned three major loci of SD brings about the essential integration needed for effective growth (development) which is determined by communication, cooperation, collaboration (together seen as COG) towards realising a synergised group quest of $\mathrm{SD}$ through a continuous process.

The aforementioned four dimensions, with particular reference to an analysis of the governance dimension, suggest that sectoral governance is coherent and capacity-building strategies are increasingly in place. However, particular challenges relate to capacity and resource constraints, for example, at local government level. The Council for Scientific and Industrial Research (CSIR) is of the opinion that '... the quality of the basic service delivery by municipalities in their respective municipal areas is deteriorating because of over-utilisation of water resources, uncontrolled urbanisation, and inadequate budget control, technical skills, planning and maintenance by municipalities in their respective municipal areas' (CSIR, 2007:10). The capacity for trans-disciplinary thinking, cross-sectoral communication, co-ordination and collaboration (COG) needs to be further strengthened by, for example, active representation and participation on public forums such as the Mooi River Forum in Potchefstroom, South Africa.

Integrating environmental considerations into sectoral policy and activities remains a key challenge for effective COG for SD. Civil society enterprises and public sector institutions need to be identified, strengthened and linked in synergetic partnerships to enhance their ability to, inter alia, monitor governments and to interact on a more equal footing with role-players such as the private sector and representative stakeholders from affected communities. All three sectors, however, require considerable education and awareness-raising with respect to an understanding of SD and the implications for public policy making.

If a country's natural resource base is under stress, it automatically creates imbalances between all the remaining pillars and sub-systems of $\mathrm{SD}$, for example, the quest for shared growth in a national drive to address poverty in a positive manner. In other words, socio-economic goals cannot be attained if the underlying ecosystems are depleted or the facilitation of the SD process is typified by, inter alia, absent or ineffective COG. Most developing countries are confronted by the need to factor the following into their economic policy making: actual fundamental threats such as the negative impact of inherited and persistent poverty and the effect that inequality and deteriorating infrastructure will have on a national quest towards improved development. Secondly, a limited extent of and underlying depletion of natural resources (i.e. inadequate energy, potable water shortages, and rising waste levels) will undermine a national drive to try and meet a country's fundamental human needs to build an advanced and sustainable economy.

The major role-players in this dimension of the SD process are primarily the private sector, civil society, influential individuals and government institutions. Due to the rising levels of diversity, complexity and the more sophisticated needs of citizens, the leading role-players are unable to achieve effective SD themselves. It is crucial for them to be visible, show interest, communicate with each other and getting to know each other's strengths and weaknesses, determine the 'rules of the game', identify each other's place and roles and co-operate and work together in a synergised manner towards achieving common goals.

With the aforementioned in mind, the nature and extent of co-operative governance (COG) will now be highlighted. 


\section{Co-operative governance (COG)}

A determining factor in the quest for better understanding of COG is a clarification of the concept 'corporate governance'. Evan (1993:24) defines it as '...the structure of authority and decision-making at the apex of an organisation'. Rossouw et al. (in Boer et al, 2003) point out that internationally it is agreed that good corporate governance hinges on four fundamental principles, namely: fairness, accountability, responsibility and transparency and that it also applies to COG among all stakeholders.

A prerequisite for effective COG is communicative rationality which entails a non-coercive, unifying, consensus building force of a discourse in which participants overcome their initial subjective views in favour of a rational agreement (Nelana, 2005). Effective implementation of any cross-sectoral policy requires that COG processes have to be established on the ground and not just considered as some form of laudable principle. One of the most important steps in moving towards operational COG is the identification of- and agreement on generic objectives by all the relevant, involved and affected sectors. This must be followed by the correct identification and development of organisational and coordinating arrangements and programmes that can effectively achieve these objectives (MacKay \& Ashton, 2004).

Nelana (2005) also highlights feedback, information sharing and co-ordination between government and civil society as crucial elements of COG. In this process, civil society participates in agenda setting and public policy formulation and implementation to address social exclusion arising from corporate globalisation. COG also enhances openness and transparency in the formulation and implementation of social-economic policy. Co-ordination also implies that civil society groups will not only initiate their own development planning processes but, will also co-ordinate these processes with government. Edigheji (in Nelana, 2005) identifies differentiated participation, resulting from 'competition' in formulation and implementation of planning that entrenches what COG seeks to resolve, namely: equalizing the voices of various stakeholders. National stakeholders have more power than the local. Among the national stakeholders, different stakeholders have different power. This dynamic interaction between political and economical sectors occurs as vertical COG as well as an interaction occurring at (for example, within the same sphere in and between departments and the private sector) the horizontal COG.

Of significance to the aforementioned objectives of COG is the existence of effective organisational arrangements (internal and external) of which two-way communication is first and foremost. This should lead to higher levels of visibility, transparency, accessibility and willingness of all committed actors to become involved and participate in a more active manner towards holistic and synergised group attempts of service delivery and SD per se. This might entail marketing the actors' strengths and/or the exposure of their weaknesses so that any new collaborative venture can be progressive.

COG, effectively facilitated can, inter alia, bring about the following:

- A structured framework for encouraging pluralist inputs, for example, to environmental policy making.

- A mechanism for building consensus.

- Higher flexibility to different circumstances.

- Application across international borders.

- Generation of more stable and legitimate public policy outcomes.

- Provision of context in which expert advice can be introduced in a fruitful manner.

- Provision of a framework which encourages environmental learning. (Meadowcroft, 1999). 
Unfortunately it has been proven that it is difficult to work in a collaborative manner and that the effort needed to implement co-operative governance, is problematic. The following reasons have been identified in this regard:

- An improved level of internal and external organisational arrangements are required to bring about more effective, efficient and economic communication, co-ordination and collaboration.

- There is growing competition for scarce natural resources, and it is likely that more conflicts will arise world-wide over water, especially in the face of climate change and desertification processes (MacKay \& Ashton, 2004).

Based on the four questions posed at the start of this article, the following information was analysed and synthesised through website and document analyses:

- Basic public information on various institutions', leading private sector enterprises' and civil society individuals' SD information and strategies made available on their individual websites on the Internet. Organisational aspects taken into account were overall visibility, access, transparency, willingness to share knowledge, track record of completed projects and institutional willingness to participate in collaborative research and development ventures.

- Leading actors' standing and roles in the respective development strategies.

- Additional information of importance regarding organising aspects such as communication, networking, integration, collaboration, co-ordination and COG.

In addition, a literature review of applicable resources was conducted.

\section{Challenges identified}

With reference to the aforementioned research review, the following challenges in a quest to facilitate improved co-operative governance can be identified:

- Multiple definitions and interpretations: Sustainable development is not a new concept (Baumgartner \& Korhonen, 2010) and it is one of the most widely used words today (Patra, 2008). However, this creates one of the first challenges for both managers and policy-makers as there are more than 90 definitions of sustainable development (Becker, 2010). Added to this challenge, sustainable development and the success of sustainability is a value judgment and it means different things to different people and organisations (Becker, 2010; Wallis, Kelly \& Graymore, 2010). There seems to be confusion about the actual definition of 'bigpicture thinking principles' such as environment, sustainable development, sub-systems of the aforementioned, organisational arrangements and COG (MacKay \& Ashton, 2004).

- Lack of an integrated approach: The order of co-operative and optimally co-ordinated deliberations and subsequent governance unfortunately is still such that 'the left hands do not know what the right hands are trying to do', 'no effective synergy between all actors involved with supposedly single-purpose driven goals' and 'domination and manipulation by government or big private sector institutions' (Lieferink, Interview). Often the responsibility for SD manifests on different government spheres with numerous role-players trying to establish sense in a co-operative form of federalism usually resulting in an un-co-ordinated quest towards un-aligned and poorly integrated goals. Some institutions fail to take the lead in the overall planning, capacitating, facilitating an effective cross-sectoral and multistakeholders co-ordination based on ongoing communication and consultation, and steering and controlling of a holistic and fully integrated SD. Confusion arises where, in some instances, matters relating to a single public activity may be governed by more than one 
institution (Bosman et al., 2004) and may still be fragmented. This fragmentation is exacerbated by disjointed and separate, autonomous line functioning organs of state which often operate independently from each other at different levels of governance (Nel \& Du Plessis, 2004).

- Lack of community involvement: How does one ensure optimal community involvement and 'buy-in'? Regarding representativity, a representative of a civil society said that: 'We go there, we eat, we drink, we sleep and then we go home empty headed' (Giese \& Sanders, 2008). Considering that currently there are more than 63300 development institutions and agencies formally listed on world registers (Uphoff, 2010), it adds to the confusion and 'needle in a hay stack' attempts when effective groupings of collaborative entities have to be established. In addition, it seems that the websites and documents of companies are visible, informative, detailed and excellent publicity and marketing tools. They unfortunately, do not reflect a clear willingness to interact, collaborate, co-ordinate or work together in partnerships through improved co-operative governance. Furthermore, they are not transparent regarding knowledge sharing or keeping a track-record of successful collaborative projects.

- Lack of effective monitoring and evaluation: Lack of appropriate monitoring, evaluation and reporting systems on performance and progress with $\mathrm{SD}$ initiatives has been reported.

- COG unsupportive of effective SD: Hall and Symes (2005) warn about COG (as a set of political principles) offering no obvious defence to the state asserting its right to be regarded as the primary and determining stakeholder... in a collaborative venture.

- Unsustainable rising levels of natural resource abuse: Rising levels of natural resource use and misuse. The natural resource bases are under pressure and the ecosystems face degradation; especially the supply of potable water and effective sanitation systems.

\section{Practical guidelines for the implementation of COG}

The following guidelines for both managers and public policy-makers, regarding the effective implementation of $\mathrm{COG}$, are presented:

- Identify and define the locus and focus: First and foremost an accurate identification of the locus (context) and focus of the development challenge(s) at hand through a systematic approach to public problem-solving should take place. Development from a 'command and control' type of state towards an 'enabling' state, a model in which the state is not proactively governing society but is more concerned with defining objectives and mustering resources from a wide variety of sources to pursue those goals, has been witnessed (Peters \& Pierre, 2001).

- Define sustainable development for the specific organisation: It is crucial that organisations and institutions define sustainable development within their organisation and community to ensure consistency of understanding and implementation. A recommended definition of SD clearly includes the economic, social and environmental dimensions (UN, 1992; UN 1997) with a focus on equity, growth and environmental maintenance (Brundtland, 1987).

- Develop and maintain effective partnerships: Establish partnerships and mechanisms where all the participants agree on how to co-operate, work together and add value to each other's contributions, rather than duplicate or compete with one another. Governments now realise that they can no longer manage on their own. They now have to try to facilitate and combine different groups of actors and arrange the integrated quests to public problem-solving. The nature and extent of this collaboration will be the key to successful achievement of common public goals (Salamon, 2002:8). With a shared understanding by all the attending entities of all the problems confronting them, some needs and solutions can be prioritised and the priorities can be assigned so that efforts for dealing with them, are focused. Once priority problems have been agreed upon, strategies for dealing with them need to be planned and worked out during discussions that include all the stakeholders. Equal and optimum 
representativity with designated suitable alternates and buy-in from all actors involved, must be realised.

- Adopt an approach of integration: Fox and Meyer (1995:65) regard integration as '...the condition in which all the parts of the total organisation are held together in a state of dynamic equilibrium; concerned with the means organisations use to co-ordinate the work between differentiated task groups.' This organisational arrangement(s) becomes important in, for example, the facilitation of integrated water resources management between organisational units within an institution like the Department of Water Affairs as well as between the institution and other stakeholders with similar goals.

- Utilise effective communication strategies: It is crucial to start by talking to people in households, small groups of concerned and involved stakeholders and to facilitate the establishment of focus groups. Clarity on theoretical aspects such as two-way communication, integration, the embedded nature of collaborative service delivery and COG must be confirmed by all participants. At the first bigger gatherings of interested parties it might be desirable to use specially trained persons as facilitators and catalysts to lead the proceedings. At these meetings a clear Terms of Reference and 'Rules of the game' must be established. Optimum attendance of- and active participation in meetings and ventures should be acknowledged as key performance areas and not merely as add-on functions. Improved two-direction horizontal communication needed for better co-ordination as well as two-direction vertical communication should be facilitated to produce a higher level of reporting and control in the final instance. Better use of modern communication media and technology to facilitate meetings of a higher standard must be facilitated.

- Develop and maintain effective leadership: Strong leadership (donors) is needed to direct and steer COG in the SD progress. There is a range of definitions for leadership and each person and organisation will have a unique definition of a leader. Many of the more popular definitions state that a leader is future oriented, initiates and facilitates change, initiates both goals and strategies, creates a culture based on shared values, influences the behaviours of both individual followers and groups, creates cohesiveness between the followers, and assists individual followers to achieve their personal goals while the whole team accomplishes the organisational goals (Nahavandi 2009; Tubbs, Husby \& Jensen 2009; Robbins, Judge, Millet \& Waters-Marsh 2008; Wells \& Hejna 2009:67).

- Develop and maintain effective systems: As some areas of sustainable development could only be assessed by inference from what is observable and not always through quantifiable measurement (Becker, 2010; Wallis, Kelly \& Graymore, 2010), continuous monitoring, reporting and evaluation systems are needed in place for more effective COG (Burger, 2009).

- Implement best practice approaches: It is fruitful to utilise best practices, lessons learnt, and to expand capacity throughout the participating community. Identify these as continuous and keep the process simple, clearly defined, well structured, properly communicated, coordinated and managed to ensure effective roll-out of SD programmes.

- Allocate and effectively manage needed resources: Adequate resources and capacity to deal with the task at hand (i.e. strengthening civil societies to act on equal footing, awareness-raising, skills development, and modern technology) are prerequisites.

- Implement a public engagement approach: Public involvement in decision-making must make provision for, inter alia, the opportunity to develop the understanding, skills and capacity necessary for achieving equal and effective participation. Community well-being and empowerment must also be promoted through environmental education, raising environmental awareness, sharing knowledge and experience and other appropriate means. All public decisions affecting the citizenry must be taken in an open and transparent manner and optimal access to public information be provided in accordance with the law.

- Manage diversity effectively: The vital role of women and youth in environmental management and development must also be recognized and their full participation therein must be 
promoted. A sincere attempt must also be made to incorporate different cultural beliefs and traditional knowledge.

The aforementioned guidelines might seem 'a bridge too far', but through an approach of one step at a time in the effective pursue of it, a positive difference in the nature and extent of co-operative governance as foundation for sustainable development, should be realised.

\section{Conclusion}

The complex integrative nature of SD makes it clear that COG, effective communication and optimum collaboration between all involved actors are essential tools for more effective SD. The interrelationships between the involved actors will inevitably reflect on the state of the environment. It is this interdependence that links them all in the first place. It is within this facilitated and established framework of COG that they must all be identified correctly and valued to their fullest.

\section{List of references}

BADEN, D.A., HARWOOD, I.A. \& WOODWARD, D.G. 2009. The effect of buyer pressure on suppliers in SMEs to demonstrate CSR practices: An added incentive or counter productive? European Management Journal, 27 (6): 429-441. DOI: 0.1016/j.emj.2008.10.004.

BAUMGARTNER, R.J. \& KORHONEN, J. 2010. Strategic thinking for sustainable development. Sustainable Development, 18: 71-75. DOI: 10.1002/sd.450.

BECKER, J. 2010. Use of back-casting to integrate indicators with principles of sustainability. International Journal of Sustainable Development \& World Ecology, 17 (3): 198-197. DOI: 10.1080/13504501003726974.

BOER, A., O'BEIRNE, S. \& GREYLING, T. 2003. The quest for co-operative environmental governance - Do stakeholders have a consistent map and directions? LALAsa2003 Annual National Conference.

BOSMAN, C., KOTZÉ, L. \& DU PLESSIS, W. 2004. The failure of the Constitution to ensure integrated environmental management from a co-operative governance perspective. (2004) 19 $S A P R / P L$.

BRUNDTLAND REPORT. 1987. Brundtland Report (Our Common Future). Retrieved from: http://www.ace.mmu.ac.uk/eae/Sustainability/Older/Brundtland Report.html. May 2010.

BULKELEY, H., DAVIES, A., EVANS, B., GIBBS, D., KERN, K., \& THEOBALD, K. 2003. Environmental Governance and Trans-national Municipal Networks in Europe. Journal of Environmental Policy \& Planning Vol. 5, No. 3, September 2003, 235-254.

BURGER, D. 2009. South Africa Yearbook 2008/09. Pretoria: SAGI. 
CHO, C.H. \& ROBERTS, R.W. 2010. Environmental reporting on the internet by America's toxic 100: Legitimacy and self-presentation. International Journal of Accounting Information Systems, 11 (1): 1-16. DOI: 10.1016/j.accinf.2009.12.003.

COUNCIL FOR SCIENTIFIC AND INDUSTRIAL RESEARCH (CSIR). 2007. The state of municipal infrastructure in South Africa and its operation and maintenance: An overview. Pretoria: CSIR.

DEPARTMENT OF ENVIRONMENTAL AFFAIRS. 2003. Co-operative Environmental Governance. Internet abstraction from: http//www.environment.gov.za/Documents/Documents/2003May21/environmental_implem entation. Accessed on 2010/05/03.

DEPARTMENT: ENVIRONMENTAL AFFAIRS AND TOURISM. 2006. People - Planet Prosperity: A Strategic Framerwork for Sustainable Development in South Africa. Pretoria: Government Printer.

EVAN, W.M. 1993. Organization Theory: Research and Design. New York: Macmillan Publishing Company.

FOX, W. \& MEYER, I.H. 1995. Public Administration Dictionary. Cape Town: Juta \& CO Ltd.

GIESE, S. \& SANDERS, B. 2008. An overview of Co-operative Governance structures relevant to children in South Africa. The Alliance for Children's Entitlement to Social Security.

GLASSON, J. \& WOOD, G. 2009. Urban regeneration and impact assessment for social sustainability. Impact Assessment and Project Appraisal, 27(4), December 2009.

HALL, M. \& SYMES, A. 2005. South African higher education in the first decade of democracy: from cooperative governance to conditional autonomy. Studies in Higher Education Vol. 30, No. 2, April 2005.

HOVERSTADT, P. \& BOWLING, D. 2005. Organisational viability as a factor in sustainable development of technology. International Journal of Technology Management and Sustainable Development Volume 4 Number 2.

ISLAM, S. M.N., MUNASINGHE, M, \& CLARKE, M. 2003. Making long-term economic growth more sustainable: evaluating the costs and benefits. Ecological Economics, Vol 49, Issue 1, 10 May 2004.

JABBOUR, C.J.C. \& SANTOS, F.C.A. 2008. The central role of human resource management in the search for sustainable organizations. The International Journal of Human Resource Management, vol 19, no 12, pp: 2133-2154.

JAMES, H. 2003. Cooperation and Community Empowerment in Myanmar in the context of Myanmar Agenda 21. Asian-Pacific Economic Literature, May 2003, Vol. 17 Issue 1, p1-21.

LIEFERINK, M. 2010. Interview: Director of Federation for a Sustainable Environment (FSE). Johannesburg, South Africa.

MACKAY, H.M. \& ASHTON, P.J. 2004. Towards co-operative governance in the development and implementation of cross-sectoral policy: Water policy as an example. Water $S A$ Vol. 30 No. 1 January 2004. 
MEADOWCROFT, J. 1999. Cooperative Management Regimes; Collaborative Problem Solving to Implement Sustainable Development. International Negotiation 4: 225-254, 1999. Kluwer Law International. Netherlands.

MORROW, D. \& RONDINELLI, D. 2002. Adopting corporate environmental management systems: Motivations and results of ISO 14001 and EMAS certification. European Management Journal, 20 (2): 159-171.

NAHAVANDI, A. 2009. The Art and Science of Leadership, $5^{\text {th }}$ Edition. New Jersey: Pearson Prentice Hall.

NEL, J. \& DU PLESSIS, W. 2004. Unpacking integrated environmental management - a step closer to effective co-operative governance? (2004) 19 SAPR/PL.

NELANA, B. 2005. Co-operative governance in integrated development planning - Local economic development in the Eastern Cape. Unpublished MPHIL dissertation, University of Stellenbosch.

PATRA, R. 2008. Vaastu Shastra: Towards sustainable development. Sustainable Development, 17 (4): 244-256. DOI: 10/1002/sd.388.

PETERS, G. \& PIERRE, J. 2001. Development in intergovernmental relations: towards multi-level governance. Policy E Politics vol 29 no 2:131-5

REPUBLIC OF SOUTH AFRICA (RSA). 1998. National Environmental Management Act no. 107 of 1998. Pretoria: Government Printer.

ROBBINS, S.P., JUDGE, T.A., MILLET, B. \& WATERS-MARSH, T. 2008. Organisational

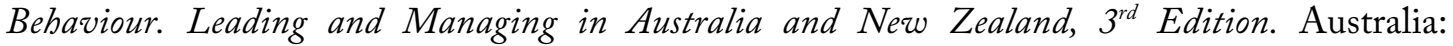
Pearson Education.

SALAMON, L.M. 2002. The Tools of Government - $A$ Guide to the New Governance. New York: Oxford University Press.

SZWAJKOWSKI, E. 2000. Simplifying the principles of stakeholder management: The three most important principles. Business and Society, Chicago, December, 39, 4, 379-397.

TORBAY COUNCIL. 2006. What is Sustainable Development? Internet online: http://www.torbay.gov.uk/vi/index/environment-planning/environmentpolicy . Accessed on 2010/06/08.

TUBBS, S.L., HUSBY, B. \& JENSEN, L. 2009. Integrating leadership development and continuous improvement practices in healthcare organizations, The Journal of American Academy of Business, 15 (1): 279-286.

UNITED NATIONS (UN). 1992. United Nations Conference on Environment \& Development, Rio de Janeiro, 14 June, Agenda 21. Retrieved from: http://www.unep.org/

UNITED NATIONS (UN). 1997. United Nations Earth Summit +5, New York, 23-27 June. Retrieved from: http://www.un.org.esa/earthsummit/

UPHOFF, N. 2010. Local Institutions and Participation for Sustainable Development. Gatekeeper Series no. SA31. USA: iied 
WALLIS, A.M., KELLY, A.R. \& GRAYMORE, L.M. 2010. Assessing sustainability: a technical fix or a means of social learning? International Journal of Sustainable Development E World Ecology, 17 (1): 67-75. DOI: 10.1080/13504500903491812.

WELLS, W. \& HEJNA, W. 2009. Developing leadership talent in healthcare organizations. Healthcare Financial Management, 63 (1): 66-69.

WSSD 2002. World Summit on Sustainable Development, Johannesburg, 26 August- 4 September. Johannesburg: WSSD. 